\title{
Recruitment and monitoring behaviors by leaders predict following in wild Barbary macaques (Macaca sylvanus)
}

\author{
Anne Seltmann ${ }^{1, \mathrm{a}}$, Mathias Franz ${ }^{2}$, Bonaventura Majolo ${ }^{3}$, Mohamed Qarro ${ }^{4}$, Julia Ostner ${ }^{1, *}$, and \\ Oliver Schülke ${ }^{1, *}$ \\ ${ }^{1}$ Department of Behavioral Ecology, Georg-August University Göttingen, Göttingen, Germany \\ ${ }^{2}$ Department of Wildlife Diseases, Leibniz Institute for Zoo and Wildlife Research, Berlin, Germany \\ ${ }^{3}$ School of Psychology, University of Lincoln, Lincoln, UK \\ ${ }^{4}$ Ecole Nationale Forestière d'Ingénieurs, Salé, Morocco \\ ${ }^{a}$ current address: Department of Evolutionary Ecology, Leibniz Institute for Zoo and Wildlife Research, \\ Berlin, Germany \\ *These authors contributed equally to this work. \\ Correspondence to: Anne Seltmann (seltmann@izw-berlin.de)
}

Received: 19 February 2016 - Revised: 23 June 2016 - Accepted: 24 June 2016 - Published: 8 July 2016

\begin{abstract}
For group-living animals it is essential to maintain the cohesiveness of the group when traveling. Individuals have to make an accurate decision about where and when to move. Communication before and during the departure of the first individual may play a crucial role in synchronizing a collective movement. We hypothesized that individuals in a wild primate group use signals or cues prior to and after departure to achieve collective movements. With two observers we used all-occurrences behavior sampling of collective movements in a group of wild Barbary macaques (Macaca sylvanus) in the Middle Atlas, Morocco. The number of individuals displaying pre-departure behavior predicted the success of an initiation of a collective movement. Pauses of the first departing individual after departure enhanced following behavior and might have served as recruitment signal. However, the opposite was the case for back-glancing, which functions as a monitoring signal in other species. Because in our study frequently back-glancing individuals were also less socially integrated, back glances may better be interpreted as indicators of hesitation and insecurity. To successfully initiate a collective movement, it seemed to be sufficient for a socially integrated group member to take action when other group members signal their willingness prior to departure and to occasionally wait for the group while moving.
\end{abstract}

\section{Introduction}

The maintenance of cohesiveness is a challenging task for a group of social animals, especially if individuals differ in physiological needs, morphological traits (e.g., body size), motivation, and knowledge about the home range (Conradt and Roper, 2005; Sueur and Deneubourg, 2011). In such heterogeneous groups, a consensus decision about a joint departure time and direction is especially difficult to achieve (Conradt and Roper, 2005; Pyritz et al., 2011). Depending on the proportion of group members involved in the decision process, equally shared consensus decisions (all group members can decide), partially shared consensus decisions (a subset of group members can decide) or unshared decisions (a single individual decides) can be used to define a specific time and direction for departure (Pyritz et al., 2011). Collective behavior resulting from consensus decisions may involve information gathering through communication and cooperation among group members (Stückle and Zinner, 2008; Fischer and Zinner, 2011b).

In partially shared and unshared consensus decisions, a form of leadership can occur: either a subgroup or one particular individual decides for a specific travel time and direction on behalf of all group members (Pyritz et al., 2011). The term "leadership" does not indicate the front position of an individual as this may change during the movement 
but the elicitation of follower behavior and the exertion of social influence on group members (Pyritz et al., 2010, 2011). Initiators of a collective group movement can try to increase the cohesiveness and the number of followers through the display of recruitment and monitoring behaviors during the collective movement, i.e., post-departure (Bourjade and Sueur, 2010; Sueur and Petit, 2010), which has been called active leadership (King et al., 2009). Initiation signals have been at least anecdotally reported in a wide range of non-human primate species, ranging from the great apes (mountain gorillas, Gorilla beringei beringei, and chimpanzees, Pan troglodytes) to Old World monkeys (Hanuman langurs, Semnopithecus entellus; capped leaf monkeys, Trachypithecus pileatus; guerezas, Colobus guereza) and New World monkeys, e.g., pygmy marmosets (Callithrix pygmaea), mantled howler monkeys (Alouatta palliata) and dusky titi monkeys (Callicebus moloch) (reviewed by Fichtel et al., 2011). Recruitment and monitoring behaviors can be pauses (interruption of the movement which exceeded $2 \mathrm{~s}$; Sueur and Petit, 2008a; 2010) and back glances (moving the head to look back at the remainder of the group) during the move, which have been described, for example, in baboons (Kummer, 1968; Stückle and Zinner, 2008), macaques (Sueur and Petit, 2010), and capuchin monkeys (Meunier et al., 2008). Pauses have been shown to increase the number of followers in Tonkean macaques (M. tonkeana; Sueur and Petit, 2008a). Pauses have been interpreted as a recruitment signal for conspecifics because they could function to convey the message about the timing and direction of a collective movement, and it has been shown in some cases that pauses can increase the number of followers (Sueur and Petit, 2008a, 2010). Alternatively, pauses could result from the insecurity of the initiator about whether or not the group was immediately following - in which case they would not have evolved as signals (King et al., 2011). A particularly fast or slow speed of movement by the initiator can increase the number of followers in white-faced capuchin monkeys (Cebus capucinus; Leca et al., 2003) and Tonkean macaques (Sueur and Petit, 2008a) and could have evolved as a signal for departure to other group members, although speed may also simply convey the degree of urgency for leaving. Primates are not the only taxon where initiators of collective movements use signals when departing (Pratt et al., 2002): in bottlenose dolphins (Tursiops sp.), for example, recruitment behavior in the form of side flops has been described before a travel bout (Lusseau and Conradt, 2009).

In a previous study on group movements in wild Barbary macaques we observed potential communication behaviors, but we did not evaluate the role of these behaviors in determining group movements (Seltmann et al., 2013). We have previously established that decisions about the timing and direction of group movements are partially shared consensus decisions. We described that during the pre-departure period both the initiator and other, mainly adult group members show pre-departure behavior (e.g., back glances) in the majority of initiation attempts. Pre-departure behaviors may serve as indicators of the willingness to move further in a certain direction at a certain time (Bourjade et al., 2009; Bourjade and Sueur, 2010; Sueur et al., 2010b). In our former analyses, we focused on the individual characteristics of predeparture displaying individuals and initiators of collective movements. We found that adult, high-ranking (male) group members had a disproportionately strong influence on collective movements (Seltmann et al., 2013).

Here we take a new perspective that focuses on assessing the role of communication in group coordination (Fischer and Zinner, 2011a). Specifically, we focus on behaviors before (number of pre-departure displaying individuals) and during a collective movement (speed, position, back glances and brief pauses of the first departing animal, i.e., the initiator). Although there have been studies on communication during collective movements in semi-free-ranging macaques, this is to our knowledge the first study on communication during collective movements conducted on wild macaques that are unrestricted in their group movements; thus it contributes to the understanding of group coordination in nonhuman primates. In our discussion we provide a table summarizing current knowledge on signals and behavioral cues that captive and wild primates use before and during a collective movement.

\section{Material and methods}

\subsection{Ethics statement}

The ethical treatment of research subjects complies with Moroccan, German and UK regulations. The Haut Commissariat des Eaux et Forêts et à la Lutte Contre la Désertification of Morocco provided permission to conduct this study. As the study was exclusively based on observations, data collection most likely did not have an impact on the monkeys' welfare. Barbary macaques are classified as an endangered species by the IUCN (2016).

\subsection{Study subjects and site}

Study animals were a wild, but well-habituated Barbary macaque group. Their home range (an area of approximately $6 \mathrm{~km}^{2}$ ) was situated in the Ifrane National Park (protected) near the town Azrou in the Middle Atlas, Morocco. The approximate location of the home range of the study group was $33^{\circ} 24^{\prime} \mathrm{N}, 5^{\circ} 12^{\prime} \mathrm{W}$. Research on the behavior and ecology of the Barbary macaques at this site has been coordinated by Bonaventura Majolo and Prof. Mohamed Qarro since 2008. The study group lived at an altitude of about 1730 to $1930 \mathrm{~m}$ a.s.1. In general, the habitat consisted of open mixed cedar and oak woodland with undergrowth. Occasionally, shepherds with sheep and dogs passed by near the edge of the home range and one road crossed through the home range. Two observers followed the study group from March 
to June 2012. The group consisted of 24 individuals: 6 adult females, 6 adult males, 1 sub-adult male (4 years) and 11 juveniles (Table 1). During the study period, six infants were born. For all analyses the single sub-adult male was included in the adult age class. Apart from the births, the group composition was stable during the study period and every individual was present on every observation day. Study subjects were all group members except the infants. All individuals were recognized from natural markings like moles, scars and fur color pattern.

\subsection{Definitions}

Preliminary observations of this group of Barbary macaques in 2011 suggested that collective movements generally begin with a single individual heading out in a certain direction, and this individual is subsequently followed by other group members. Such an initiation movement is often preceded by shorter directed movements and back glances by the same initiator or other group members. To exactly define group movement related terms, we conducted a 2-week pilot study as suggested by Pyritz et al. (2010) for this social group of Barbary macaques. Details of the pilot study have been described elsewhere (Seltmann et al., 2013) and yielded the following definitions:

- Incentive movement (pre-departure behavior): a direct walk of an animal, for a distance shorter than $18 \mathrm{~m}$ and that did not result, within $2 \mathrm{~s}$, in feeding, social interactions, lying down or climbing a tree. Incentive movements are only qualified when taking place before an initiation movement (see below).

- Initiation movement: a movement of an individual in a directed manner with a minimum distance of $18 \mathrm{~m}$ as straight as environmental conditions allow (bypassing natural obstacles, such as deep valleys, was still included in the definition of straight forward) without pausing for more than $2 \mathrm{~s}$. Movements within a social context, e.g., chasing or approaching another individual, or as a response to alarm calls were excluded. To qualify as an initiation movement, at least three individuals needed to be more than $11 \mathrm{~m}$ behind the initiator.

- Initiator: the individual performing an initiation movement.

- Collective movement: an initiation movement that resulted in a group departure (all individuals of the group move to another location). The collective movement starts with the initiation movement and ends with the termination (see below).

- Termination: the initiation movement ended when the initiator was stationary again for at least $3.5 \mathrm{~min}$.

- Followers: group members moving behind the initiator were called followers unless their movements diverged
Table 1. Composition of the study group including information on age class, ordinal dominance rank, social integration, number of initiation movements and mean (range) number of followers. $\mathrm{M}$ - male, F - female, SM - sub-adult male, JM/JF - juvenile male/female. * Individuals were already fully grown at the beginning of habituation of the group 3 years ago; exact age is therefore not known. CIS - composite index of social integration. See methods for details.

\begin{tabular}{|c|c|c|c|c|c|c|}
\hline ID & Sex & Age & Rank & CIS & $\begin{array}{l}\text { Initiation } \\
\text { attempts }\end{array}$ & $\begin{array}{l}\text { Number of } \\
\text { followers }\end{array}$ \\
\hline $\mathrm{Oz}$ & M & adult* & 1 & 0.86 & 49 & $4(0-14)$ \\
\hline $\mathrm{Ar}$ & M & adult* & 2 & 0.96 & 23 & $6(0-20)$ \\
\hline Lw & M & adult* & 3 & 0.77 & 29 & $6(0-17)$ \\
\hline $\mathrm{Ge}$ & M & adult* & 4 & 0.39 & 43 & $4(0-16)$ \\
\hline $\mathrm{Si}$ & M & 6 years & 5 & 0.79 & 12 & $6(1-14)$ \\
\hline $\mathrm{Nd}$ & M & adult* & 6 & 0.5 & 31 & $5(0-18)$ \\
\hline An & $\mathrm{F}$ & adult* & 7 & 1.25 & 25 & $5(0-15)$ \\
\hline $\mathrm{Mc}$ & M & 4 years & 8 & 0.87 & 6 & $4(0-11)$ \\
\hline $\mathrm{Da}$ & $\mathrm{F}$ & adult* & 9 & 1.46 & 12 & $6(0-12)$ \\
\hline Jo & $\mathrm{F}$ & adult* & 10 & 0.71 & 9 & $3(0-10)$ \\
\hline $\mathrm{Ke}$ & $\mathrm{F}$ & adult* & 11 & 0.81 & 16 & $5(0-12)$ \\
\hline $\mathrm{Rb}$ & $\mathrm{F}$ & adult* & 12 & 0.96 & 13 & $5(0-14)$ \\
\hline $\mathrm{He}$ & $\mathrm{F}$ & adult* & 13 & 0.72 & 3 & $2(0-5)$ \\
\hline Dk & $\mathrm{F}$ & 3 years & 14 & 1.28 & 5 & $4(2-6)$ \\
\hline $\mathrm{Aj}$ & M & 2 years & 16 & 1.47 & 1 & $12(\mathrm{n} / \mathrm{a})$ \\
\hline $\mathrm{Kr}$ & $\mathrm{F}$ & 3 years & 16 & 0.98 & 0 & $\mathrm{n} / \mathrm{a}$ \\
\hline $\mathrm{Rf}$ & M & 2 years & 16 & 1.34 & 0 & $\mathrm{n} / \mathrm{a}$ \\
\hline $\mathrm{Kl}$ & M & 2 years & 18 & 1.21 & 2 & $6(0-12)$ \\
\hline $\mathrm{Ak}$ & M & 1 year & 19 & 1.51 & 1 & $6(\mathrm{n} / \mathrm{a})$ \\
\hline Dn & $\mathrm{F}$ & 2 years & 20 & 1.47 & 0 & $\mathrm{n} / \mathrm{a}$ \\
\hline $\mathrm{Jj}$ & M & 1 year & 21 & 1.16 & 0 & $\mathrm{n} / \mathrm{a}$ \\
\hline Do & $\mathrm{F}$ & 1 year & 22 & 1.34 & 2 & $3(3-3)$ \\
\hline Hs & M & 1 year & 23 & 1.20 & 1 & $2(\mathrm{n} / \mathrm{a})$ \\
\hline Rl & $\mathrm{F}$ & 1 year & 24 & 1.23 & 0 & $\mathrm{n} / \mathrm{a}$ \\
\hline
\end{tabular}

more than $45^{\circ}$ from the initiator's trajectory. Otherwise, the direction was considered as different and the individual may have been an initiator of a different movement. Followers had to arrive within an $11 \mathrm{~m}$ radius around the initiator, no later than $3.5 \mathrm{~min}$ after the termination of the movement.

\subsection{Behavioral observations}

All occurrences sampling (Altmann, 1974) was used to record collective movements. The identity of group members conducting pre-departure behavior (incentive movements or back glances, Sueur et al., 2010a, b) was recorded directly and simultaneously by two observers: one focused on the front and the other on the center of the group. A direct walk of an animal, for a distance shorter than $18 \mathrm{~m}$ and that did not result, within $2 \mathrm{~s}$, in feeding, social interactions, lying down or climbing a tree, was defined as an incentive movement. To measure distances we used a high-accuracy $( \pm 2 \mathrm{~mm})$ laser device (PLR 50, Bosch, Munich, Germany). 
A back glance was defined as a turn of an individual's head of more than $90^{\circ}$, excluding those performed during feeding or social interactions. Directions of pre-departure behaviors of an individual that differed from each other by an angle of more than $45^{\circ}$ were considered to be different (Sueur et al., 2010a, b). Once one individual initiated a group movement, one observer followed the initiator. The observer recorded the identity of the initiator, if the initiator was at the front of the group at any point of the movement (see Fig. 1 for details); the speed of the initiator (walk, walk fast, or run); back glances and pauses of the initiator during the movement, whether the initiator sat facing the group during a pause of his movement or after termination; and the identity of followers. Pauses were defined as stops during the movement which exceeded $2 \mathrm{~s}$ after the initiator completed the initial distance of $18 \mathrm{~m}$ (Sueur and Petit, 2008a, 2010). Back glances from the initiator were recorded regardless of the context. When dogs, their barks or cars disturbed the monkeys, no data were collected for the following $20 \mathrm{~min}$. The terrain and forest environment is in general open mixed cedar and oak woodland with little undergrowth, so that the group was easily observable most of the time.

Information concerning the social centrality of individuals was acquired via instantaneous scan sampling (Altmann, 1974) every hour outside a moving context. We recorded, for each group member, the number of individuals (1) in body contact, (2) that were within $1.5 \mathrm{~m}$ and (3) within $5 \mathrm{~m}$; all surrounding individuals were only accounted for once, in the closest possible category. If study subjects could not be found after $15 \mathrm{~min}$, they were discarded from the scan. If one individual initiated a group movement during a scan sampling session, the scan was cancelled. We only included scans with more than $80 \%$ of group members present $(N=122)$ in the analysis and discarded the others $(N=9)$.

Information about dominance relations between individuals was acquired via ad libitum recording of agonistic behavior (aggression: lunge, charge, chase, slap, grab, jump on, bite, ground slap, run towards, open mouth, head bob; submission: make room, give ground, flee, crouch, present submission, fear scream; Berghänel et al., 2010). An interaction was rated as decided if only two monkeys were involved in a conflict, one or none of the animals showed aggressive behavior and the other acted submissively. In total, 850 decided conflicts were recorded.

During the pilot study we observed every group member for $20 \mathrm{~min}$, except one 1-year-old juvenile that was limping during the period of the pilot study, using focal animal sampling in six different time slots equally distributed over the day, yielding a total of 46 focal hours. During the focal protocols the frequency of back glances was recorded to compare this rate later on with the rate of the initiator displaying back glances during group movements.
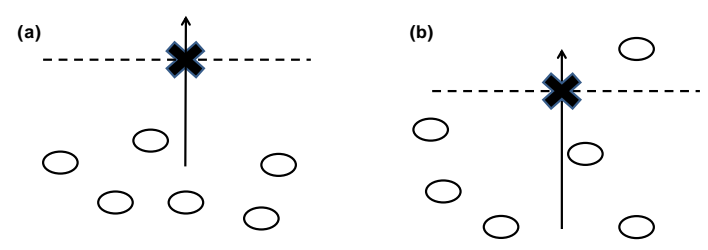

(c)
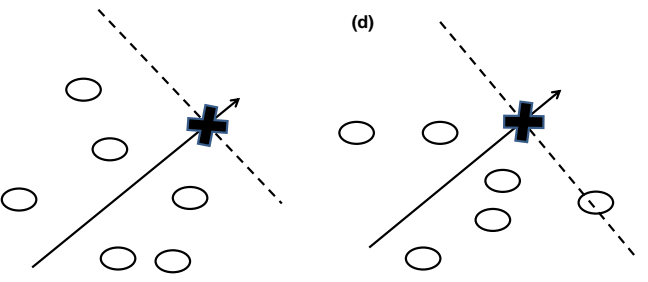

Figure 1. Front position of the initiator. To qualify as being at the front of the group, no group members (open ovals) must be positioned (moved there or already be there during the initiation movement) at or in front of the imaginary line (dashed line) perpendicular to the initiator's (cross) trajectory (arrow). (a, c) The initiator is at the front of the group. (b, d) Initiator is not at the front of the group.

\subsection{Statistical analyses}

All statistical tests were conducted in R-3.2.3 (R Core Team, 2015). Tests were two-tailed and the significance level was set to $\alpha=0.05$. If not reported otherwise, means and standard errors are given in the format $X \pm$ SEM. A Wilcoxon matched-pairs test was conducted to compare the rate of back glances during the focal protocols of the pilot study and initiation movements for individuals that tried to initiate a movement at least twice $(N=16)$. If an individual changed the direction of its pre-departure behavior, the most recent one was taken into account and the preceding ones discarded.

A chi-squared test was conducted to test whether every individual had the same probability to be in the scans (chi-squared test: $\chi^{2}=1.59, \mathrm{df}=23, P=1$ ). By combining the three parameters measuring body contact and interindividual distance (within 1.5 or $5 \mathrm{~m}$; see above), we estimated the centrality of individuals in the social network as their composite index of social integration (CIS). This was done similar to Sapolsky et al. (1997) and Silk et al. (2003) as follows:

$\mathrm{CIS}=\frac{\sum_{i=1}^{3} \frac{x_{i}}{m_{i}}}{3}$,

where $x_{i}$ was the value for individuals in (1) body contact, (2) at a distance up to $1.5 \mathrm{~m}$, and (3) between 1.5 and $5 \mathrm{~m}$; $m_{i}$ is the group's median values for (1)-(3).

The dominance hierarchy was constructed by calculating the normalized David's score via the win proportions $P_{i j}$ (de Vries et al., 2006) and was found to be linear (MatMan, males: Landau index $h^{\prime}=0.93$, females: $h^{\prime}=1$, juveniles: $h^{\prime}=0.99$; de Vries, 1995). 
Table 2. Effect of predictor variables on the number of followers in initiation movements $(N=283), \mathrm{SE}-\mathrm{standard}$ error, ${ }^{*} P<0.05$, ** $P<0.01$ and ${ }^{* * *} P<0.001$.

\begin{tabular}{|c|c|c|c|c|}
\hline Effects & Estimate & SE & $Z$ & $P$ \\
\hline \multicolumn{5}{|c|}{ Pre-departure behavior } \\
\hline Pre-departure of the initiator (yes) & 0.03 & 0.08 & 0.32 & 0.753 \\
\hline Number of pre-departure displaying individuals & 0.14 & 0.02 & 8.56 & $<0.001^{* * *}$ \\
\hline \multicolumn{5}{|c|}{ Post-departure behavior of the initiator } \\
\hline Rate of back glances/minute & -0.29 & 0.09 & -3.25 & $0.001^{* *}$ \\
\hline Rate of pauses/minute & 0.31 & 0.15 & 2.15 & $0.031^{*}$ \\
\hline Speed (walk fast) & 0.04 & 0.21 & 0.18 & 0.860 \\
\hline Speed (walk) & 0.13 & 0.17 & 0.79 & 0.43 \\
\hline Front position (yes) & -0.07 & 0.08 & -0.83 & 0.41 \\
\hline Facing group (yes) & -0.03 & 0.08 & -0.41 & 0.68 \\
\hline \multicolumn{5}{|c|}{ Individual characteristics of the initiator } \\
\hline Rank of the initiator & 0.01 & 0.02 & 0.67 & 0.504 \\
\hline CIS of the initiator & 0.56 & 0.21 & 2.75 & $0.006^{* *}$ \\
\hline Sex of the initiator (male) & 0.32 & 0.14 & 2.24 & $0.025^{*}$ \\
\hline
\end{tabular}

In total, we observed 283 initiation movements on 25 days from 20 April to 8 June 2012 (mean 11.32, range: 1-23 per day). A summary of individual initiation movements and respective numbers of followers can be found in Table 1. We used a generalized linear mixed effects model with binomial error distribution (GLMM) to determine which predictors influence the number of followers in a collective movement. For each observed initiation movement we used as the response the number of individuals of the group that followed the initiator of the collective movement (given a maximum possible number of 23 followers in each case). We included the following predictor variables that describe post-departure behaviors of the initiator: (1) the rate of back glances and (2) the rate of pauses of the initiator during the collective movement, (3) whether the initiator was at any point at the front of the group, (4) whether the initiator was sitting facing the group during a pause, and (5) the speed of the initiator, i.e., walk, walk fast, or run. Additionally, we included predictor variables that describe pre-departure behavior: (6) whether the initiator showed pre-departure behavior and the (7) number of pre-departure displaying individuals. Because we know that the following behavior of group members depends on individual characteristics of the initiator (Seltmann et al., 2013), we additionally included (8) the rank of the initiator, (9) the CIS of the initiator and (10) the sex of the initiator. In addition we included the (11) identity of the initiator and (12) observation day as a random variable to control for unrecorded individual effects and nonindependence of initiation events. The estimated variance of the random variables was 0.015 (identity of the initiator) and 0.187 (observation day). For our analyses we used the R packages "MASS" and "Ime4" (Venables and Ripley, 2002; Bates et al., 2014). The fitting of the GLMM was based on Laplace approximation, and $p$ values for all fixed effects were calculated based on $Z$ tests.

\section{Results}

\subsection{Effect of pre- and post-departure behaviors on the number of followers}

Results of our GLMM showed that the number of followers significantly increased with pre-departure behavior (the number of pre-departure displaying individuals: GLMM, estimate $=0.14, \mathrm{SE}=0.02, Z=8.56, p<0.001, n=283$; Fig. 2), post-departure behavior of the initiator (the rate of pauses per minute of the initiator: GLMM, estimate $=0.31$, $\mathrm{SE}=0.15, Z=2.15, p=0.031)$ and individual characteristics of the initiator (high CIS: GLMM, estimate $=0.56$, $\mathrm{SE}=0.21, Z=2.75, p=0.006$; sex (male) of the initiator: GLMM, estimate $=0.32, \mathrm{SE}=0.14, Z=2.24, p=0.025)$. In addition, the number of followers significantly decreased with another post-departure behavior of the initiator: the rate of back glances per minute by the initiator (GLMM, estimate $=-0.29, \mathrm{SE}=0.09, Z=-3.25, p=0.001$; Fig. 3, Table 2).

\subsection{The use of back glances}

As we found that the rate of back glances had a significant negative effect on the number of followers and the success of an initiation movement, we further investigated the use of back glances. During preliminary studies, we observed that back-glancing is a frequent behavior and occurs for example in feeding and social contexts. We wanted to find out whether Barbary macaques used back glances in 


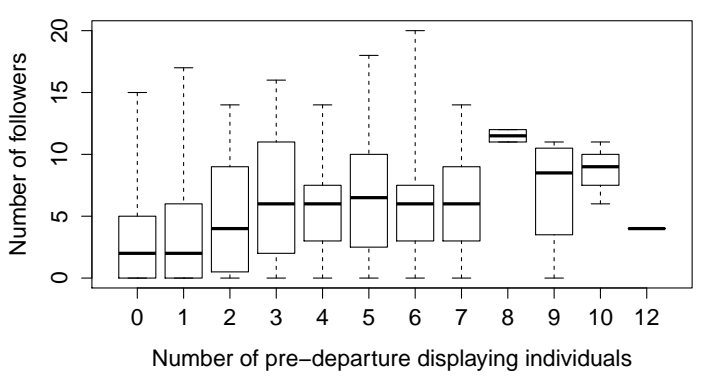

Figure 2. Effect of pre-departure behavior on the number of followers. The number of followers significantly increased with the number of pre-departure displaying individuals prior to departure $(\mathrm{GLMM}$, estimate $=0.14, \mathrm{SE}=0.02, Z=8.56, N=283$, $p<0.001$ ). The figure shows medians (bold line), 25-75th percentiles (box), 5-95th percentiles (whiskers) and outliers (points).

the context of initiation movements more than average. Indeed, we found that initiators displayed more back glances during initiation movements than in other situations (initiation: $0.42 \pm 0.23$ per minute, control: $0.29 \pm 0.26$ per minute; Wilcoxon matched-pairs test: $V=122, N=16, P<0.05)$. We found that the lower the CIS of an individual, the higher the average rate of back glances they displayed during an initiation movement (Spearman rank correlation: $\rho=-0.47$, $N=19, P<0.05)$ : more socially integrated individuals displayed the behavior less often.

\section{Discussion}

We found that successful initiation of collective movement was predicted by the number of pre-departure displaying individuals and post-departure behaviors of the initiator (rate of back-glancing and pausing). Speed, sitting facing the group, dominance rank of the initiator and front position in the group did not influence initiation success. Individual characteristics of the initiator (social integration and male sex) played a role in the elicitation of following behavior as well.

Most of the behaviors by the initiator did not influence the number of followers of a movement. The lack of an effect of the initiator's front position on the number of followers at any time during the movement corroborates earlier findings that the term "leader" does not simply imply the front position of an animal during group movements and that hidden leadership may occur (Pyritz et al., 2011). As has been found in captive rhesus macaques (Sueur and Petit, 2008a) and wild chacma baboons (Papio ursinus, Stückle and Zinner, 2008), the speed of the initiator's movement did not affect the number of followers. This is in contrast to observations on Tonkean macaques and white-faced capuchins where speed affects the joining process (Leca et al., 2003; Sueur and Petit, 2008b).

Confirming the findings of our previous study and like in Tonkean macaques, we found that the success of an individ-

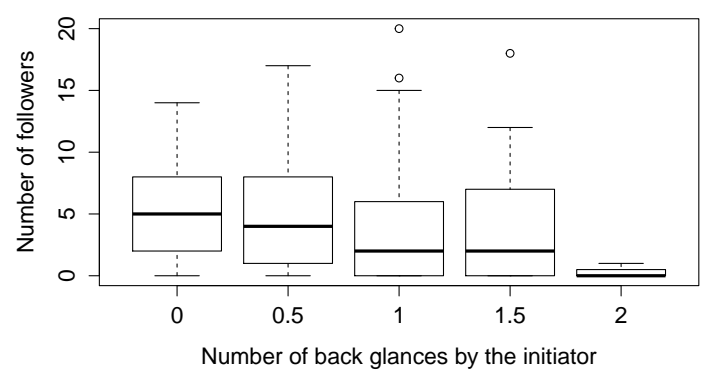

Figure 3. Effect of back glances on the number of followers. The number of followers significantly decreased with the rate of back glances by the initiator during the collective movements (GLMM, estimate $=-0.29, \mathrm{SE}=0.09, Z=-3.25, N=283, p=0.001)$. For reasons of clearer representation we rounded the rate of back glances to 0.5 per minute. The figure shows medians (bold line), 25-75th percentiles (box), 5-95th percentiles (whiskers) and outliers (points).

ual's attempts to initiate a collective movement is not predicted by dominance rank, but by social integration if including juveniles in the analyses (Sueur and Petit, 2008a; Seltmann et al., 2013). In rhesus macaques (M. mulatta), both social integration and a high dominance rank favored a positive outcome of an initiation movement (Sueur and Petit, 2008a). In contrast to olive baboons (Papio anubis), in Japanese macaques (M. fuscata) and white-faced capuchin monkeys, dominance rank influenced the success of an individual's attempts to initiate a collective movement, but social integration was not assessed (Leca et al., 2003; Jacobs et al., 2011; Strandburg-Peshkin et al., 2015).

In addition to individual characteristics of the initiator (Seltmann et al., 2013), communication of the initiator after departure proved to play a pivotal role during collective movements. Specifically, in addition to social integration, two post-departure behaviors by the initiator significantly influenced the following behavior of group members: the rate of back glances and pauses. In our study, as in Tonkean and rhesus macaques, the rate of back glances had a significantly negative effect on the elicitation of following behavior (Sueur and Petit, 2008a, 2010). In chacma baboons, back glances did not influence the success of an initiation at all (King et al., 2011). A possible explanation for back-glancing is the monitoring function (Sueur and Petit, 2010). However, if enough individuals follow the movement of the initiator, there is no need for the initiator to further watch its group members. However, if only a few or no individuals follow the initiator, it may continue to glance backwards to see whether they follow and eventually stop going further or even return to the group. The function of glancing backwards has been interpreted not only as a recruitment signal or cue for conspecifics, but also as an index of hesitation and uncertainty of the initiator caused by the low number of followers (Meunier et al., 2008; Sueur and Petit, 2010; King et al., 2011). Our results support the latter explanation. Individuals may pre- 
Table 3. Comparative data on Barbary macaques (this study, wild group), rhesus macaques (semi-free-ranging conditions), Tonkean macaques (semi-free-ranging conditions), white faced capuchin monkeys (semi-free-ranging conditions) and Chacma baboons (wild group).

\begin{tabular}{|c|c|c|c|c|c|}
\hline & $\begin{array}{l}\text { Rhesus } \\
\text { macaques }\end{array}$ & $\begin{array}{l}\text { Barbary } \\
\text { macaques }\end{array}$ & $\begin{array}{l}\text { Tonkean } \\
\text { macaques }\end{array}$ & $\begin{array}{l}\text { White-faced } \\
\text { capuchin } \\
\text { monkeys }\end{array}$ & $\begin{array}{l}\text { Chacma } \\
\text { baboons }\end{array}$ \\
\hline $\begin{array}{l}\text { Type of } \\
\text { consensus } \\
\text { decision }\end{array}$ & $\begin{array}{l}\text { partially } \\
\text { shared }\end{array}$ & $\begin{array}{l}\text { partially } \\
\text { shared }\end{array}$ & $\begin{array}{l}\text { equally } \\
\text { shared }\end{array}$ & $\begin{array}{l}\text { partially } \\
\text { shared }\end{array}$ & $\begin{array}{l}\text { partially } \\
\text { shared }\end{array}$ \\
\hline $\begin{array}{l}\text { Occurrence } \\
\text { of recruitment } \\
\text { behavior during } \\
\text { collective } \\
\text { movements }\end{array}$ & $34 \%^{1}, 70 \%^{2}$ & $78 \%$ & $75 \%^{2}$ & $51 \% 4$ & unknown \\
\hline $\begin{array}{l}\text { Success } \\
\text { enhancing speed }\end{array}$ & not specific ${ }^{3}$ & not specific & fast $^{3}$ & slow $^{4}$ & not specific 5 \\
\hline $\begin{array}{l}\text { Effect of back } \\
\text { glances on } \\
\text { success }\end{array}$ & $\begin{array}{l}\text { none }^{3 /} \\
\text { negative }^{2}\end{array}$ & negative & negative ${ }^{2,3}$ & positive $^{4}$ & none ${ }^{6}$ \\
\hline $\begin{array}{l}\text { Effect of pauses } \\
\text { on success }\end{array}$ & $\begin{array}{l}\text { none }^{3} / \\
\text { negative }^{2}\end{array}$ & positive & $\begin{array}{l}\text { none }^{2} / \\
\text { positive }^{3}\end{array}$ & none ${ }^{4}$ & $\begin{array}{l}\text { none }^{5 /} \\
\text { negative }^{6}\end{array}$ \\
\hline
\end{tabular}

fer to follow initiators who are determined to depart and do not show signs of hesitation in the form of repeatedly glancing backwards. It remains unclear, however, whether the high rate of back glances is caused by a low number of followers or vice versa.

In contrast, a second recruitment behavior, pausing during the initiation movement, increased the number of followers as it has been reported for Tonkean macaques (Sueur and Petit, 2008a, but see Sueur and Petit, 2010). Yet in other primates (white-faced capuchin monkeys, rhesus macaques, and chacma baboons) there was either no or a negative effect of pauses by the initiator on the following behavior of group members (Leca et al., 2003; Stückle and Zinner, 2008; Sueur and Petit, 2008a, 2010).

In our analyses we ignored the role of vocalizations which in some species can function as cues or signals during group coordination (e.g., Hanuman langurs, Vogel, 1973; guerezas, Oates, 1977; pygmy marmosets, Soini, 1981; yellow baboons, Papio cynocephalus, Norton, 1986; chacma baboons, Fischer and Zinner, 2011b; red-fronted lemurs, Eulemur rufifrons, Pflüger and Fichtel, 2012; woolly lemurs, Avahi occidentalis, Ramanankirahina et al., 2015). In our case, however, only $5 \%$ of collective movements were associated with grunt vocalizations by the initiator of the movement or other group members and these were equally frequent during successful and unsuccessful initiations.

Taking our results together, we propose that successful initiators of collective movements chose the timing for depar- ture according to the quorum represented by the number of pre-departure displaying individuals (Pratt et al., 2002; Sueur et al., 2010a) and used pauses to recruit group members once they initiated the collective movement. However, successful initiators do not rely on back glances as monitoring behavior during traveling.

Table 3 summarizes these results and highlights the diverse use of recruitment behaviors within monkeys. Barbary macaques show the most similarities to Tonkean macaques, which are one of the most egalitarian, tolerant and individualistic macaque species where dyadic asymmetries and strong kin preferences are uncommon (Thierry, 2004). Apart from this, there is no obvious pattern across species and studies. The behavior of the initiator shortly before and during an attempt to initiate a group movement may have a positive, negative or no effect on the behavior of followers, and effects may differ between different behaviors. The fact that the same initiator behavior had different effects (absent or positive/negative) on potential followers in different social groups of the same species seems to suggest that the behavior (a particular fast or slow speed, pauses and back glances) did not evolve as a signal, i.e., that it was not selected for the change in behavior it caused in the receiver of the signal (Maynard Smith and Harper, 2003). It seems more likely that potential followers can but will not always read the behavior of the initiator as a cue; whether they do so and what they take from the cue varies within and between species. 


\section{Data availability}

The data und R code underyling the GLMM can be downloaded at https://zenodo.org/record/57260.

Acknowledgements. We are grateful to the Haut Commissariat des Eaux et Forêts et à la Lutte contre la Désertification of Morocco for permission to conduct research in Ifrane National Park. We are very grateful to Bashira Chowdhury for her indispensable assistance in data collection. We thank Chris Young, Anna Nesbit, and Laetitia Maréchal for advice and support in Morocco. We are grateful to Chris Young for advice in data analyses and to Elke Zimmermann, Dietmar Zinner, and one anonymous reviewer for valuable comments on the manuscript.

The authors declare that they have no conflict of interest.

This open-access publication was funded

by the University of Göttingen.

Edited by: E. Zimmermann

Reviewed by: D. Zinner and one anonymous referee

\section{References}

Altmann, J.: Observational study of behaviour: sampling methods, Behaviour, 49, 227-265, 1974.

Bates, D., Maechler, M., Bolker, B., and Walker, S.: _lme4: Linear mixed-effects models using Eigen and S4_, R package version 1.1-7, http://www.CRAN.R-project.org/package=lme4 (last access: 13 January 2016), 2014.

Berghänel, A., Schülke, O., and Ostner, J.: Coalition formation among Barbary macaque males: the influence of scramble competition, Anim. Behav., 80, 675-682, 2010.

Bourjade, M. and Sueur, C.: Shared or unshared consensus to move collectively? Towards methodological concerns, Behav. Process., 84, 648-652, 2010.

Bourjade, M., Thierry, B., Maumy, M., and Petit, O.: Decision making in Przewalski horses (Equus ferus przewalskii) is driven by the ecological contexts of collective movements, Ethology, 115, 321-330, 2009.

Conradt, L. and Roper, T.: Consensus decision making in animals, Trends Ecol. Evol., 20, 449-456, 2005.

de Vries, H.: An improved test of linearity in dominance hierarchies containing unknown or tied relationships, Anim. Behav., 50, 1375-1389, 1995.

de Vries, H., Stevens, J. M. G., and Vervaecke, H.: Measuring and testing the steepness of dominance hierarchies, Anim. Behav., 71, 585-592, 2006.

Fichtel, C., Pyritz, L., and Kappeler, P. M.: Coordination of group movements in non-human primates, in: Coordination in human and primate groups, edited by: Boos, M., Kolbe, M., Kappeler, P. M., and Ellwart, T., Springer-Verlag, Berlin, Heidelberg, 37-56, 2011.

Fischer, J. and Zinner, D.: Communication and cognition in primate group movement, Int. J. Primatol., 32, 1279-1295, 2011a.

Fischer, J. and Zinner, D.: Communicative and cognitive underpinnings of animal group movement, in: Coordination in human and primate groups, edited by: Boos, M., Kolbe, M., Kappeler, P. M., and Ellwart, T., Springer-Verlag, Berlin, Heidelberg, 229-244, $2011 b$.

GLMM: Dataset and R code of " Recruitment and monitoring behaviors by leaders predict following in wild Barbary macaques (Macaca sylvanus)", https://zenodo.org/record/57260, last access: July 2016.

IUCN: Red List of Threatened Species, Version 2015-4, http:// www.iucnredlist.org, last access: 16 May 2016.

Jacobs, A., Watanabe, K., and Petit, O.: Social structure affects initiations of group movements but not recruitment success in Japanese macaques (Macaca fuscata), Int. J. Primatol., 32, 13111324, 2011.

King, A. J., Johnson, D. D. P., van Vugt, M.: The origins and evolution of leadership, Curr. Biol., 19, R911-R916, 2009.

King, A. J., Sueur, C., Huchard, E., and Colishaw, G.: A rule-ofthumb based on social affiliation explains collective movements in desert baboons, Anim. Behav., 82, 1337-1345, 2011.

Kummer, H.: Social organization of Hamadryas baboons - a field study, S. Karger AG, Basel, New York, 1968.

Leca, J. B., Gunst, N., Thierry, B., and Petit, O.: Distributed leadership in semi-free ranging white-faced capuchin monkeys, Anim. Behav., 66, 1045-1052, 2003.

Lusseau, D. and Conradt, L.: The emergence of unshared consensus decisions in bottlenose dolphins, Behav. Ecol. Sociobiol., 63, 1067-1077, 2009.

Maynard Smith, J. and Harper, D. G. C.: Animal Signals, Oxford University Press, Oxford, 2003.

Meunier, H., Deneubourg, J. L., and Petit, O.: How many for dinner? Recruitment and monitoring by glances in capuchins, Primates, 49, 26-31, 2008.

Norton, G.W.: Leadership decision processes of group movement in yellow baboons, in: Primate ecology and conservation, edited by: Else, J. G. and Lee, P. C., Cambridge University Press, Cambridge, 145-156, 1986.

Oates, J. F.: The guereza and its food, in: Primate ecology, edited by: Clutton-Brock, T. H., Academic, London, 276-321, 1977.

Pflüger, F. J. and Fichtel, C.: On the function of red-fronted lemur's close calls, Anim. Cognit., 15, 823-831, 2012.

Pratt, S. C., Mallon, E. B., Sumpter, D. J. T., and Franks, N. R.: Quorum sensing, recruitment, and collective decision-making during colony emigration by the ant Leptothorax albipennis, Behav. Ecol. Sociobiol., 52, 117-127, 2002.

Pyritz, L. W., Fichtel, C., and Kappeler, P. M.: Conceptual and methodological issues in the comparative study of collective group movements, Behav. Process., 84, 681-684, 2010.

Pyritz, L. W., King, A. J., Sueur, C., and Fichtel, C.: Reaching a consensus: Terminology and concepts used in coordination and decision making research, Int. J. Primatol., 32, 1268-1278, 2011.

Ramanankirahina, R., Joly, M., Scheumann, M., Zimmermann, E.: The role of acoustic signaling for spacing and group coordination in a nocturnal, pair-living primate, the western woolly lemur (Avahi occidentalis), Am. J. Phys. Anthropol., 159, 466-477, 2015.

R Core Team: R: A language and environment for statistical computing, R Foundation for Statistical Computing, Vienna, Austria, http://www.R-project.org (last access: 11 January 2016), 2015. 
Sapolsky, R. M., Alberts, S. C., and Altmann, J.: Hypercortisolism associated with social subordinance or social isolation among wild baboons, Arch. Gen. Psychiatr., 54, 1137-1143, 1997.

Seltmann, A., Majolo, B., Schülke, O., and Ostner, J.: The organization of collective group movements in wild Barbary macaques (Macaca sylvanus): Social structure drives processes of group coordination in macaques, PLoS ONE, 8, e67285, doi:10.1371/journal.pone.0067285, 2013.

Silk, J. B., Alberts, S. C., and Altmann, J.: Social bonds of female baboons enhance infant survival, Science, 302, 1231-1234, 2003.

Soini, P.: The pygmy marmoset, genus Cebuella, in: Ecology and behavior of Neotropical primates, edited by: Mittermier, R. A., Rylands, A. B., and Coimbra-Filho, A. F., Academia Brasileira de Ciencias, Rio de Janeiro, 79-129, 1981.

Strandburg-Peshkin, A., Farine, D. R., Couzin, I. D., and Crofoot, M. C.: Shared decision-making drives collective movement in wild baboons, Science, 348, 1358-1361, 2015.

Stückle, S. and Zinner, D.: To follow or not to follow: decision making and leadership during the morning departure in Chacma baboons, Anim. Behav., 75, 1995-2004, 2008.

Sueur, C. and Deneubourg, J. L.: Self-Organization in Primates: Understanding the rules underyling collective movements, Int. J. Primatol., 32, 1413-1432, 2011.
Sueur, C. and Petit, O.: Shared or unshared consensus decisions in macaques?, Behav. Process., 78, 84-92, 2008a.

Sueur, C. and Petit, O.: Organization of group members at departure is driven by social structure in Macaca, Int. J. Primatol., 29, 1085-1098, 2008b.

Sueur, C. and Petit, O.: Signals use by leaders in Macaca tonkeana and Macaca mulatta: group mate recruitment and behaviour monitoring, Anim. Cognit., 13, 239-248, 2010.

Sueur, C., Deneubourg, J. L., and Petit, O.: Sequence of quorums during collective decision making in macaques, Behav. Ecol. Sociobiol., 64, 1875-1885, 2010a.

Sueur, C., Petit, O., and Deneubourg, J. L.: From the first intention movement to the last joiner: macaques combine mimetic rules to optimize their collective decisions, P. Roy. Soc., 278, 1697-1704, 2010b.

Thierry, B.: Social epigenesis, in: Macaque societies: A model for the study of social organization, edited by: Thierry, B., Singh, M., and Kaumanns, W., Cambridge University Press, Cambridge, 267-289, 2004.

Venables, W. N. and Ripley, B. D.: Modern applied statistics with S, 4th Edn., Springer, New York, 2002.

Vogel, C.: Acoustical communication among free-ranging common Indian langurs (Presbytis entellus) in two different habitats of North India, Am. J. Phys. Anthropol., 38, 469-480, 1973. 